\title{
Physiotherapy
}

Physiotherapy xxx (2019) xxx-xxx

\section{Outcomes of physical activity for people living with dementia: qualitative study to inform a Core Outcome Set}

\author{
Ana-Carolina Gonçalves ${ }^{\mathrm{a}, \mathrm{b}}$, Alda Marques ${ }^{\mathrm{c}}$, Dinesh Samuel ${ }^{\mathrm{a}}$, Sara Demain ${ }^{\mathrm{d}, *}$ \\ a School of Health Sciences, Faculty of Environmental and Life Sciences, University of Southampton, Southampton, United \\ Kingdom \\ b Solent NHS Trust, Southampton, United Kingdom \\ ${ }^{\mathrm{c}}$ School of Health Sciences (ESSUA) and Institute of Biomedicine (iBiMED), University of Aveiro, Aveiro, Portugal \\ ${ }^{\mathrm{d}}$ School of Health Professions University of Plymouth, Plymouth, United Kingdom
}

\begin{abstract}
Background The need for a Core Outcome Set to evaluate physical activity interventions for people living with dementia, across stages of disease and intervention settings has been established. This qualitative study precedes the consensus phase of developing this Core Outcome Set and aims to: (i) compare the outcomes identified by patients, carers and professionals to those previously reported in the literature; (ii) and understand why certain outcomes are considered important.

Design and methods In-depth semi-structured interviews were conducted with people living with dementia, family carers and professionals $(n=29)$. The outcomes identified in the interviews were mapped to a list of outcomes reported in a recent literature review. An in-depth thematic analysis was conducted to understand the importance of physical activity in dementia care.

Results A comprehensive, inductively derived list of 77 outcomes, common across stages of dementia and intervention setting, was put together for the consensus phase of this Core Outcome Set: ten of these were new outcomes generated by this qualitative study. Five themes explained why stakeholders perceived physical activity outcomes as important for people living with dementia: "being well and staying well", "having a role towards others", "maintaining identity", "being connected to the present" and "delivering good quality care".

Conclusion Ten new outcomes of physical activity, not previously reported in recent literature, were identified. Physical activity is considered important to people living with dementia due to its positive impact on multiple health outcomes for both patients and carers.

(C) 2019 Chartered Society of Physiotherapy. Published by Elsevier Ltd. All rights reserved.
\end{abstract}

Keywords: Physical activity; Dementia; Core Outcome Set; Qualitative study

\section{Introduction}

Dementia is a major cause of dependency and disability among older people, resulting in increased burden on individuals, carers and health care services [1]. The need for research into interventions to improve care of people living with dementia is evident [2]. Physical activity, defined by

\footnotetext{
* Corresponding author. Present address: School of Health Professionals, Peninsula Allied Health Centre, University of Plymouth, Devon, PL6 8BH, United Kingdom.

E-mail addresses: A.C.Goncalves@soton.ac.uk (A.-C. Gonçalves), amarques@ua.pt (A. Marques), D.Samuel@soton.ac.uk (D. Samuel), sara.demain@plymouth.ac.uk (S. Demain).
}

the World Health Organization as "any bodily movement produced by skeletal muscles that requires energy expenditure", may be one such intervention. Despite the large number of available studies, guidance on the ideal dose of physical activity for people living with dementia is lacking. A recent literature review [3] identified substantial heterogeneity of outcomes reported in physical activity research for people living with dementia. This is one factor limiting meta-analyses and the establishment of robust conclusions in this field. The development of a Core Outcome Set - a minimum set of outcomes to be measured across trials of a particular intervention and/or health condition [4] - has therefore been recommended for physical activity interventions for 
people with dementia [3]. This Core Outcome Set has been designed to be applicable across stages of disease progression and intervention settings [3] to maximise homogeneity in this field of research, knowing that specific outcomes for different stages of disease, types of dementia or activity settings can still be measured by researchers, in addition to those recommended by the Core Outcome Set [4].

A gold standard for Core Outcome Set development is yet to be defined. The inclusion of qualitative methods preceding the consensus phase of Core Outcome Set development, represents a methodological innovation considered particularly necessary when research in the field of the Core Outcome Set lacks sufficient qualitative work [5]. Most qualitative studies about physical activity for people with dementia are linked to a specific intervention and are aimed at exploring feasibility, barriers and facilitators to that intervention [6-10]. The few available qualitative papers, not linked to a specific intervention, include only care home settings $[11,12]$ or people living with early stages of dementia $[13,14]$ and do not meet the needs of a Core Outcome Set applicable across intervention settings, types of dementia and stages of the condition. Furthermore, these qualitative studies are not centred on intervention outcomes, and therefore many outcomes, relevant to participants, may have been missed during data collection.

Views of multiple stakeholders - patients, carers and professionals - may facilitate the selection of meaningful outcomes for this Core Outcome Set, leading to the implementation of tailored interventions, in research and clinical practice, as recommended in dementia research and policy [15].

The present qualitative study aimed to inform the next stage (a consensus study) of a Core Outcome Set to evaluate physical activity interventions for people with dementia by (i) comparing the outcomes identified by professionals, carers and patients against those previously described in the literature and (ii) gaining a deeper understanding of why certain outcomes are considered important in dementia care.

\section{Design and methods}

The present study was reported according to the consolidated criteria for reporting qualitative research (COREQ) [16].

\section{Recruitment and patient and public involvement}

Recruitment visits were made to support groups, exercise groups and dementia related activities and events. Posters were made available in public spaces (e.g. libraries, churches, social centres) and flyers distributed via gatekeepers in charities and support groups. The study poster and a short description of this research was made available through websites and newsletters of professional organisations. Participants interested in taking part contacted the research team using the contact details provided on posters and flyers. Infor- mation about the study was provided to potential participants (verbally and in a writing via the participant information sheet). A date for interview was only arranged with those who wanted to participate. A phone call was made the day before the interview to offer any further clarifications and confirm the interview date. Formal consent was recorded on the day of the interview.

This study benefited from patient and public involvement during recruitment and data analysis. A former carer of a person living with dementia, who also had a role as a leader in a carer support group, assisted the team to identify local dementia services and advised on strategies to approach gatekeepers in those organisations. This strategy had a very positive impact on recruitment for this study. She also contributed to the data analysis, by discussing findings with the authors as the analysis progressed.

\section{Inclusion criteria}

The following participants were included:

- People with a diagnosis of dementia, with capacity to consent to take part in research at the time of data collection and able to communicate verbally in English;

- Family members who were currently involved or had previously been involved in the care of a relative living with dementia;

- Professionals who have been involved in promoting, designing or supporting physical activity for people with dementia.

\section{Exclusion criteria}

People living with dementia were excluded if they had been bedridden since before the diagnosis. Family members were excluded if they were not in contact with the person with dementia since their diagnosis. Professionals were excluded if their professional role in dementia care was undertaken exclusively outside of the United Kingdom. Exclusion criteria were discussed with those who expressed an interest in taking part.

\section{Sampling}

Purposive sampling was used, aiming for a maximum variation strategy [17] across stakeholder groups, using the following criteria:

- Stage of disease progression, determined by the MiniMental State Examination score, completed by the first author (interviewer) immediately prior to the interview: "Mild to moderate" - 17 to 26; "Moderate to severe" - 10 to 16 and "Severe" - less than 10 [18];

- Type of dementia;

- Activity setting (i.e. community, care or nursing homes, assisted living; hospital); 
- Levels of physical activity, determined by the score on the Physical Activity Scale for the Elderly [19], completed immediately before the interview, with input from the carer; Scores range from zero (no physical activity completed in the previous seven days) to 693.9 (maximum physical activity level score);

- Socioeconomic deprivation, determined by the Index of Multiple Deprivation [20], using the participants' post code, with scores ranging from 1 (most deprived) to 10 (least deprived).

Recruitment aimed to reach data saturation, which was defined as the point where new data being collected made little or no difference to the codes being generated from the data analysis [21].

\section{Data collection}

In-depth semi-structured interviews were conducted and audio-recorded by the first author [ACG], a female clinical doctoral research fellow and physiotherapist with previous experience of conducting qualitative studies and, at the time of data collection, was a senior clinician in an Older Person's Mental Health in-patient service, including a dementia ward. Participants were aware of the professional background of the interviewer. Reflective notes were written after each interview.

The interview topic guide was designed to enable participants to discuss outcomes of physical activity and explore the importance of such outcomes. Professionals and carers were interviewed face-to-face or remotely (via telephone or video call), according to their preference. People living with dementia were interviewed face-to-face, in a private venue of their choice, and encouraged to have a relative or friend with them at all times. During the interviews with people living with dementia, the following strategies were used, based on previous research [22], and the interviewer's [ACG] experience of communicating with people with living with dementia: asking simple questions, giving time for the person to answer, rephrasing the question with help from the carer, maintaining good eye contact, reading body language for signs of fatigue or distress, offering breaks and choosing the time and venue for the interview according to the person's needs. These strategies also facilitated the capacity assessment. Capacity to consent to research was assessed based on the British Psychological Society guidance [23]. When present, the carer helped the researcher to explain the study to the person with dementia, providing all possible opportunities to make an informed decision. Carers were also encouraged to note any signs of discomfort or distress, which may indicate the need to stop the interview.

\section{Data analysis}

To address the aims of this study, two separate types of analysis were completed. Both analysis' steps were completed predominantly by the first author, with regular guidance and in consultation with other authors.

Aim 1: Interviews were transcribed verbatim and analysed thematically [24]. The transcripts were not returned to the participants for comments or corrections. Initial inductive (data driven) and semantic codes (close to the participants' own words) were used across the data set, to identify potential outcomes of physical activity. An outcome was defined as "a perceived consequence or impact, positive or negative, for people living with dementia, their carers or health services, whether intended or incidental, arising from undertaking physical activity". Codes with equivalent semantic meanings were merged and grouped into higher level codes (outcome domains). At this stage, a deductive approach was used, and the outcome domains were compared, by two independent researchers [ACG and a researcher independent from this research team], against the outcome domains previously reported in the literature [3]. A merged final list of outcome domains was created and the scope of each outcome domain defined.

Aim 2: Outcome domains were thematically organised, by identifying patterns and connections between outcomes that could be described by a higher level theme [24]. Each theme represented a meaningful concept to answer the question: "why is physical activity important to people living with dementia?" The final data analysis was presented back to four participants for member checking [25].

\section{Results}

\section{Participant characteristics}

Interviews were conducted with 29 participants (5 people living with dementia; 14 carers and 10 professionals). The average interview duration was 67 minutes, ranging from 35 to 101 minutes. Table 1 describes the sample characteristics. Previous research suggests that interviews involving people in severe stages of dementia can be triangulated with interviews of their carers [26]. When it was not possible to gather the views of the person living with dementia, the carer was interviewed instead, aiming to get as close as possible to the views of those at the later stages of dementia. In this study, nine of the carers interviewed, were carers of people living with severe dementia and/or people with dementia who were unable to communicate verbally or provide consent.

\section{Aim 1: Comparing outcome domains generated by this study, against those found in the literature}

A final list of 77 outcome domains (60 positive/beneficial) was generated. Fig. 1 illustrates the process of defining this list of outcome domains. Of the final 77 outcome domains, 10 (8 positive/beneficial) were new outcomes generated by this qualitative study and not reported in the literature; nine (4 
Table 1

Sample characterisation.

\begin{tabular}{|c|c|c|}
\hline Stakeholder group 1: people with dementia and their carers $(n=19)$ & $\begin{array}{l}\text { Mean (SD) or } n(\%) \\
\text { People living with dementia }\end{array}$ & $\begin{array}{l}\text { Mean }(\mathrm{SD}) \text { or } n \\
(\%) \\
\text { Carers }\end{array}$ \\
\hline \multicolumn{3}{|l|}{ Role } \\
\hline People living with dementia & $5(26 \%)$ & - \\
\hline Spouses & - & $6(32 \%)$ \\
\hline Adult children or children in law & - & $8(42 \%)$ \\
\hline \multicolumn{3}{|l|}{ Demographics } \\
\hline Age (years) & $75(11.8)$ & $62(12.4)$ \\
\hline Gender (female) & $3(60 \%)$ & $10(71 \%)$ \\
\hline Levels of physical activity & $58.5(74.0)$ & - \\
\hline Mini Mental State Examination & $19.2(3.9)$ & - \\
\hline Index of Multiple Deprivation & $7.8(1.9)$ & $6(2.7)$ \\
\hline \multicolumn{3}{|l|}{$\begin{array}{l}\text { Experience of doing or supporting activity in which of the following } \\
\text { setting }(s)\end{array}$} \\
\hline Community & $3(60 \%)$ & $9(64 \%)$ \\
\hline Care or nursing home & $2(40 \%)$ & $2(14 \%)$ \\
\hline Assisted living & $0(0 \%)$ & $4(29 \%)$ \\
\hline Hospital & $0(0 \%)$ & $2(14 \%)$ \\
\hline \multicolumn{3}{|l|}{$\begin{array}{l}\text { Living with the following stage of disease progression or having } \\
\text { experience of supporting activity for a relative through the following } \\
\text { stage(s) of disease progression }\end{array}$} \\
\hline Mild to moderate & $4(80 \%)$ & $6(43 \%)$ \\
\hline Moderate to severe & $1(20 \%)$ & $0(0 \%)$ \\
\hline All stages & - & $7(50 \%)$ \\
\hline Not known & - & $1(7 \%)$ \\
\hline \multicolumn{3}{|l|}{ Type of dementia } \\
\hline Alzheimer's disease & $2(40 \%)$ & $9(64 \%)$ \\
\hline Mixed dementia & $1(20 \%)$ & $1(7 \%)$ \\
\hline Vascular dementia & $1(20 \%)$ & $1(7 \%)$ \\
\hline Lewy body dementia & $0(0 \%)$ & $2(14 \%)$ \\
\hline Young onset Alzheimer's disease & $1(20 \%)$ & $0(0 \%)$ \\
\hline Not Known & $0(0 \%)$ & $1(7 \%)$ \\
\hline Stakeholder group 2: professionals $(n=10)$ & Mean (SD) or $n(\%)$ & \\
\hline \multicolumn{3}{|l|}{ Role } \\
\hline Physiotherapists & $4(40 \%)$ & \\
\hline Occupational Therapists & $2(20 \%)$ & \\
\hline Activity coordinators & $1(10 \%)$ & \\
\hline Charities & $2(20 \%)$ & \\
\hline Private companies & $1(10 \%)$ & \\
\hline Involved in delivering research & $1(10 \%)$ & \\
\hline \multicolumn{3}{|l|}{ Demographics } \\
\hline Age (years) & $43(10.1)$ & \\
\hline Gender (female) & $5(50 \%)$ & \\
\hline \multicolumn{3}{|l|}{ Professional setting } \\
\hline Community & $7(70 \%)$ & \\
\hline Care or nursing home & $7(70 \%)$ & \\
\hline Hospital & $4(40 \%)$ & \\
\hline \multicolumn{3}{|l|}{ Experience per stage of disease progression } \\
\hline $\begin{array}{l}\text { Experience in care for people with mild to } \\
\text { moderate dementia }\end{array}$ & $1(10 \%)$ & \\
\hline $\begin{array}{l}\text { Experience in care for people at all stages } \\
\text { of dementia }\end{array}$ & $9(90 \%)$ & \\
\hline
\end{tabular}

positive/beneficial) had been identified previously but were not mentioned by participants in this study. Tables $2 \mathrm{a}$ and $2 \mathrm{~b}$ highlight these outcome domains, presented per stakeholder group, stage of disease progression and activity setting. An extended version of these tables including all 77 outcome domains, which will be considered in the consensus phase, can be found in supplementary material.
Most outcome domains (69 out of 77) were reported by both stakeholder groups, in multiple settings and dementia stages (Tables 2a, 2b and supplementary material). Data saturation was reached in both stakeholder groups, with no new outcome domains being generated by the last professional interview and only two new outcomes generated in the last patient/carer interview. 
Outcome domains identified in this qualitative study, but not previously identified in the literature $(n=10)$

NEW Outcome domains identified in this qualitative study, and not previously identified in the literature $(n=10)$

\begin{tabular}{|c|c|c|c|c|c|c|c|c|c|}
\hline \multirow{2}{*}{$\begin{array}{l}\text { Outcome domain } \\
\text { identified: }\end{array}$} & \multirow[t]{2}{*}{ Scope } & \multicolumn{2}{|l|}{ Stakeholder } & \multicolumn{3}{|l|}{ Stage } & \multicolumn{3}{|l|}{ Setting } \\
\hline & & $\begin{array}{l}\text { Prof. and } \\
\text { researchers }\end{array}$ & $\begin{array}{l}\text { Patients and } \\
\text { carers }\end{array}$ & $\begin{array}{l}\text { Mild to } \\
\text { moderate }\end{array}$ & $\begin{array}{l}\text { Moderate to } \\
\text { severe }\end{array}$ & Severe & Community & Institution & Hospital \\
\hline \multicolumn{10}{|c|}{ Positive outcome domains $(n=8)$ : } \\
\hline Improving posture & Includes sitting and standing posture. & $\mathrm{x}$ & $\mathrm{x}$ & $\mathrm{x}$ & $\mathrm{x}$ & $\mathrm{x}$ & $\mathrm{x}$ & - & $\mathrm{x}$ \\
\hline $\begin{array}{l}\text { Managing lower limb } \\
\text { oedema }\end{array}$ & Fluid retention in the lower limbs. & - & $\mathrm{x}$ & - & - & $\mathrm{x}$ & $\mathrm{x}$ & - & $\mathrm{x}$ \\
\hline Managing pressure ulcers & $\begin{array}{l}\text { Preventing pressure ulcers and recovering skin } \\
\text { integrity. }\end{array}$ & $\mathrm{x}$ & $\mathrm{x}$ & $\mathrm{x}$ & $\mathrm{x}$ & $\mathrm{x}$ & $\mathrm{x}$ & - & $\mathrm{x}$ \\
\hline Preventing incontinence & $\begin{array}{l}\text { Regularly using the toilet, by mobilising to the } \\
\text { toilet or commode instead of using a pad. }\end{array}$ & - & $\mathrm{x}$ & - & - & $\mathrm{x}$ & $x$ & - & $\mathrm{x}$ \\
\hline $\begin{array}{l}\text { Carer developing } \\
\text { friendships and peer } \\
\text { support }\end{array}$ & $\begin{array}{l}\text { Family carers meeting other relatives of people } \\
\text { living with dementia and developing a network } \\
\text { of friendship and peer support. }\end{array}$ & $\mathrm{x}$ & $\mathrm{x}$ & $\mathrm{x}$ & $\mathrm{x}$ & $\mathrm{x}$ & $\mathrm{x}$ & - & $\mathrm{x}$ \\
\hline $\begin{array}{l}\text { Meeting individual needs } \\
\text { of patient and family }\end{array}$ & $\begin{array}{l}\text { Meeting individual needs of the person living } \\
\text { with dementia. These includes identity, physical, } \\
\text { spiritual, emotional and social needs. Meeting } \\
\text { tailored needs of families. }\end{array}$ & $\mathrm{x}$ & $\mathrm{x}$ & $\mathrm{x}$ & $\mathrm{x}$ & $\mathrm{x}$ & $\mathrm{x}$ & $\mathrm{x}$ & $\mathrm{x}$ \\
\hline $\begin{array}{l}\text { Becoming interested and } \\
\text { gaining interest of } \\
\text { others }\end{array}$ & $\begin{array}{l}\text { Gaining the interest of the person living with } \\
\text { dementia and the interest of staff, formal carers } \\
\text { and relatives. Getting relatives and formal carers } \\
\text { to know the person with dementia and becoming } \\
\text { interested in what they can do. }\end{array}$ & $\mathrm{x}$ & $\mathrm{x}$ & $\mathrm{x}$ & $\mathrm{x}$ & $\mathrm{x}$ & $\mathrm{x}$ & $\mathrm{x}$ & $\mathrm{x}$ \\
\hline $\begin{array}{l}\text { Reframing and revisiting } \\
\text { the person with } \\
\text { dementia }\end{array}$ & $\begin{array}{l}\text { Recovering one's "old self" even if for brief } \\
\text { moments. Relatives having moments of seeing } \\
\text { the "old" person with dementia by seeing them } \\
\text { active as they were before the diagnosis. } \\
\text { Relatives and staff or formal carers being } \\
\text { surprised by the ability of the person living with } \\
\text { dementia. Using activity to highlight what the } \\
\text { person with dementia can still do. }\end{array}$ & $\mathrm{x}$ & $\mathrm{x}$ & $\mathrm{x}$ & $\mathrm{x}$ & $\mathrm{x}$ & $\mathrm{x}$ & $\mathrm{x}$ & - \\
\hline \multicolumn{10}{|c|}{ Negative outcome domains or risks of physical activity $(n=2)$ : } \\
\hline $\begin{array}{l}\text { Eating or drinking } \\
\text { something harmful }\end{array}$ & $\begin{array}{l}\text { Eating or drinking something that should not be } \\
\text { ingested, by confusing it with real food or drink. }\end{array}$ & $\mathrm{x}$ & $\mathrm{x}$ & $x$ & $\mathrm{x}$ & $\mathrm{x}$ & $x$ & - & - \\
\hline $\begin{array}{l}\text { Not being able to sleep } \\
\text { after an activity }\end{array}$ & $\begin{array}{l}\text { This was linked to possible changes of } \\
\text { environment or routine caused by the activity } \\
\text { (e.g. coming back to care after having been on } \\
\text { holiday). }\end{array}$ & - & $\mathrm{x}$ & - & $\mathrm{x}$ & $\mathrm{x}$ & - & $\mathrm{x}$ & - \\
\hline
\end{tabular}

"prof and researchers" - professionals and researchers; "patients and carers" - people living with dementia and their informal carers or relatives. Boxes identified with " $x$ " indicate that the outcome domain has been identified in that context. Boxes identified with "-" indicate that an outcome domain has not been identified in that particular context. 
Table $2 b$

Outcome domains measured and referred to in the literature, but not identified in this qualitative study $(n=9)$.

Outcome domains measured or referred to in the literature, but NOT identified in this qualitative study $(n=9)$

\begin{tabular}{|c|c|c|c|c|c|c|c|c|c|}
\hline \multirow{2}{*}{$\begin{array}{l}\text { Outcome domain } \\
\text { identified: }\end{array}$} & \multirow[t]{2}{*}{ Scope } & \multicolumn{2}{|l|}{ Stakeholder } & \multicolumn{3}{|l|}{ Stage } & \multicolumn{3}{|l|}{ Setting } \\
\hline & & $\begin{array}{l}\text { Prof. and } \\
\text { researchers }\end{array}$ & $\begin{array}{l}\text { Patients and } \\
\text { carers }\end{array}$ & $\begin{array}{l}\text { Mild to } \\
\text { moderate }\end{array}$ & $\begin{array}{l}\text { Moderate to } \\
\text { severe }\end{array}$ & Severe & Community & Institution & Hospital \\
\hline \multicolumn{10}{|c|}{ Positive outcome domains $(n=4)$} \\
\hline Carer mobility & $\begin{array}{l}\text { Carer mobility and balance, ability to walk with } \\
\text { less joint pain. }\end{array}$ & $\mathrm{x}$ & $\mathrm{x}$ & $\mathrm{x}$ & $\mathrm{x}$ & $\mathrm{x}$ & $\mathrm{x}$ & - & - \\
\hline Carer mood & Simply described as "carer mood". & $\mathrm{x}$ & - & - & $\mathrm{x}$ & - & $\mathrm{x}$ & - & - \\
\hline Carer quality of life & $\begin{array}{l}\text { Carer wellbeing and quality of life. At times } \\
\text { linked to carer burden. }\end{array}$ & $\mathrm{x}$ & - & $\mathrm{x}$ & $\mathrm{x}$ & $\mathrm{x}$ & $\mathrm{x}$ & - & $\mathrm{x}$ \\
\hline Carer sleep & Improved carer sleep quality. & $\mathrm{x}$ & - & - & $\mathrm{x}$ & - & $\mathrm{x}$ & - & - \\
\hline \multicolumn{10}{|c|}{ Negative outcome domains or risks of physical activity $(n=5)$} \\
\hline $\begin{array}{l}\text { Being admitted to hospital } \\
\text { or experiencing a } \\
\text { deterioration in health }\end{array}$ & $\begin{array}{l}\text { Being hospitalized or admitted to an emergency } \\
\text { department. Experiencing a deterioration of } \\
\text { overall health or becoming too unwell to } \\
\text { continue activity. }\end{array}$ & $\mathrm{x}$ & - & $\mathrm{x}$ & $\mathrm{x}$ & $\mathrm{x}$ & $\mathrm{x}$ & $\mathrm{x}$ & - \\
\hline Discovering cysts & Ganglion cyst. & $\mathrm{x}$ & - & $\mathrm{x}$ & - & - & $\mathrm{x}$ & - & - \\
\hline $\begin{array}{l}\text { Feeling dizzy, nauseous } \\
\text { or fainting }\end{array}$ & $\begin{array}{l}\text { Feeling dizzy, nauseous or light-headed. Having } \\
\text { a syncopal episode. }\end{array}$ & $\mathrm{x}$ & - & $\mathrm{x}$ & $\mathrm{x}$ & $\mathrm{x}$ & $\mathrm{x}$ & - & - \\
\hline Increasing mortality & $\begin{array}{l}\text { Number of deaths during activity or within the } \\
\text { time period while the person with dementia was } \\
\text { a participant in an activity intervention. }\end{array}$ & $\mathrm{x}$ & - & $\mathrm{x}$ & $\mathrm{x}$ & $\mathrm{x}$ & $\mathrm{x}$ & $\mathrm{x}$ & - \\
\hline Moving into care & $\begin{array}{l}\text { Being placed into an institution for permanent } \\
\text { full-time care. }\end{array}$ & $\mathrm{x}$ & - & $\mathrm{x}$ & $\mathrm{x}$ & $\mathrm{x}$ & $\mathrm{x}$ & - & - \\
\hline
\end{tabular}

"prof. and researchers" - professionals and researchers; "patients and carers" - people living with dementia and their informal carers or relatives. Boxes identified with " $\mathrm{x}$ " indicate that the outcome domain has been identified in that context. Boxes identified with "-" indicate that an outcome domain has not been identified in that particular context. 


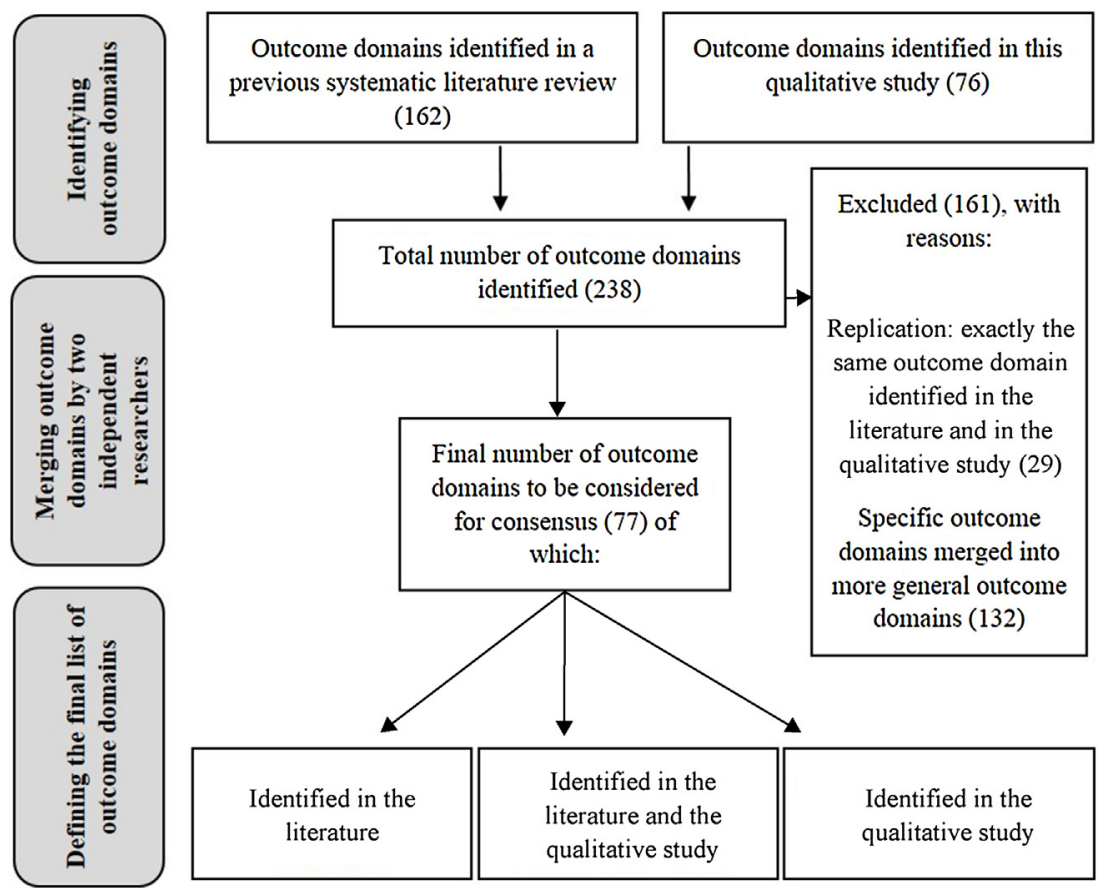

Fig. 1. Flowchart of the development of final list of outcome domains to be considered in the next phase:consensus study.

\section{Aim 2: Understanding why physical activity is important}

Five core themes explained the importance of physical activity. All themes were described across stages of disease, intervention settings, and incorporated the views of both stakeholder groups (professionals and patients/carers). There were no opposing views between stakeholders. The generated themes are described below.

\section{Being well and staying well}

Participants across all stakeholder groups reported using physical activity to improve or maintain multiple aspects of health and wellbeing of the person living with dementia, keeping an overall state of wellness - physical, cognitive and emotional - despite the diagnosis of dementia.

"Mental and physical health. I mean as a starting, as a baseline point. You are better, you are in better health, the more you get to do it. (...) Well, I mean physical stamina, strength, these things support everything. Body and mind are connected. (...) It is promoting health. It promotes health across the board." Occupational therapist (Participant ID: S2P02 All stages - Care homes).

"It gets me out of my routine, because (...) if I was at home, and things like that, it would drive me up the wall." Person living with dementia (Participant ID: S1P03P mild to moderate stages - home).

The data demonstrated that potential positive health benefits of physical activity for people living with dementia are often influenced by other factors: participants weighed up the benefits against the burden that physical activity may gener- ate for people living with dementia; and the extent to which supporting physical activity was beneficial or detrimental to carers. All stakeholder groups also expressed concerns about the potential for increased physical activity increasing the risk of falls:

"Interviewer [ACG]: would anything stop you from walking? Participant: NO! No. (...) Unless you fall flat on your face." Person living with dementia (Participant ID: S1P05P Moderate to severe stages - home)

The negative effects or burden of physical activity were not only related to accidents and injuries but also to a range of emotional and behavioural negative effects, such as becoming agitated or distressed, feeling exhausted or not being able to sleep after the activity.

"Interviewer [ACG]: You said you stopped the ball game because (...) she was aggressive. .." Participant: "It wasn't an aggression as in it didn't cause harm to anyone, but the way she was kicking. It was a bit forceful, with quite a grimaced face so that would demonstrate to me that she wasn't particularly happy about this task." Occupational Therapist (Participant ID: S2P08 All stages - Hospital).

Carers also reported on the burden of supporting activity: increased workload from keeping the person living with dementia active, while managing their own health; and perceived negative emotions associated with the activity, such as responsibility, boredom, guilt and worry.

"To be honest I think it was like a tedious kind of thing to do [walking with her mother up and down the corridor] because it was very slow and... I mean but it did feel like it was a 
good thing to do. I did feel it was like a good thing to do. But I did find it a little bit tedious. And I would feel quite anxious that mum might fall and she was anxious! And I would be very tired as well by this stage..." Daughter (Participant ID: S1P02R All stages - Community).

Conversely, it was suggested that carers also had positive experiences of keeping the person with dementia active, such as bonding with the person living with dementia during the activity, having quality time together, developing support networks with peers and improving their own health.

"I think that it is quite bonding because I think they are learning more about their family." Activity coordinator (Participant ID: S2P10 All stages - Nursing home).

In addition, carers could see their burden of care being alleviated by witnessing an improved behaviour from the person with dementia and ensuring their functional independence.

"I think we hadn't really thought ahead, to when mum would lose her mobility... what would we do then? Or how would we cope? So it seemed very important [to keep her mobile]" Daughter (Participant ID: S1P02R All stages - Community).

Maintaining independence was not only considered important for managing carer burden, but also key for people living with dementia:

"Well, you need exercise, don't you? Otherwise you just would just tighten up and wouldn't be able to do things, surely. Person living with dementia (Participant ID: S1P04P Mild to moderate stages - Care home)

When supported by others, activity was also an opportunity to give family carers a break.

"In respect to the fact that I know John is somewhere doing something he enjoys, that is independent of me, he is not reliant on me for that at all, I don't have a huge part in it, he has his own friends down there, he has something that is entirely his. And it is a form of activity. It gives me free time..." Wife (Participant ID: S1P01R Mild to moderate stages - Community).

\section{Maintaining identity}

This theme related to a continuity of identity that was achieved through activity, by enabling people living with dementia to do what they are passionate about. Activity was described by patients, carers and professionals, as a means by which the person with dementia could stay in control, keep life as "normal as possible" and minimize the disruption caused by the diagnosis of dementia.

"I suppose it is important... it sort of, as far as you can, just carry on! You know, it might not be as normal but, just do what you can! As long as you can!" Person living with dementia (Participant ID: S1P01P Mild to moderate stages Community).

\section{Having a role towards others}

Activity was also reported to be used as a source of social benefits; fighting loneliness and isolation.

"Because I imagine it can be a very lonely existence [to live with dementia], and if, if through sport in general, or whatever, that can be improved, that can only be fantastic." Private company (Participant ID: S2P06 All stages - Community).

Activity generated benefits such as feeling included, gaining a sense of belonging to groups, teams and being active members of society. It also allowed people with dementia to maintain or assume new roles, giving meaning to a new stage of life. It offered people with dementia the opportunity of being interested in a cause and feeling valued, by gaining interest from others.

"That's why I came here [became a volunteer in a gardening centre]. Just to be able to help them (...), because I know what it is like (...) and now I understand how the team gets together and do it. You know what I mean? It is great!" Person living with dementia (Participant ID: S1P03P Mild to moderate stages - Community).

\section{Being connected to the present}

While the diagnosis of dementia was described by participants as taking the person away to a difficult-to-access "dementia world", activity was described as an anchor to the present. It is a way of retrieving positive memories and emotions to the present and "living in the moment". Whilst active, people with dementia aimed to have a fulfilling time, filled with opportunities and new experiences. "Being active" was seen as having a positive, proactive attitude of wanting to be alive and wanting to fight the hopelessness of the diagnosis.

"So, so yeah if you've got, if you have just been diagnosed I would say: try not to be put off by the bigger picture. (...) And try and still do things. (...) Do things that they are used to do. But differently. So sort of fight the dementia if you like. Not fight against it, because you can't. Hopefully we will get a cure one day, but actually still do things in spite of it if you like." Daughter (Participant ID: S1P09R All stages Community and Care home).

"Well, because it [gardening] gets me to stay out and being alive." Person living with dementia (Participant ID: S1P03P Mild to moderate stages - home).

\section{Delivering good quality care}

For those providing formal or informal care, delivering activity that people living with dementia could adhere to was considered part of delivering "good care". It was considered "good" because it was cost-effective and specialised for dementia. Participants also reported that providing activity promotes a positive reputation for institutional settings. 
"From the perspective of the retirement community, (...) I think they liked the fact that it reflected well on them, that they were doing this, so they (...) had it permanently on their website and things like that." Private company (Participant ID: S2P06 All stages - Community and residential homes).

Providing activity also promoted staff satisfaction and retention. From the perspective of family carers, the provision of physical activity helped them feel that they had chosen the right care for their loved one.

For the carers [live-in carers, privately funded by relatives], you know, our job is to keep the carers content. If we can keep them happy we can keep them. And changing a live-in carer is a challenge as you can imagine. Son (Participant ID: S1P14R Stage not known - Community).

\section{Discussion}

This qualitative study precedes the consensus phase of developing a Core Outcome Set to be used to evaluate physical activity interventions for people with dementia, and represents an innovative methodological approach in Core Outcome Set development. To our knowledge this is also the first qualitative study exploring outcomes of physical activity across dementia types and stages of disease progression, and first qualitative study being published as a pre consensus phase of a Core Outcome Set. A list of 77 outcome domains, including 10 novel outcome domains, was developed. Most outcome domains were relevant across stakeholders, settings and stages of disease progression, and were organised under five themes: "Being well and staying well", "Maintaining identity", "Having a role towards with others", "Being connected to the present" and "Delivering good quality care". This study makes two distinct contributions to knowledge: it informs the development of Core Outcome Set methodology; provides new in-depth knowledge about the importance of physical activity in dementia care.

\section{Implications for Core Outcome Set methodology}

A total of 10 outcome domains would have been missed in the consensus phase, had this qualitative study not been undertaken. This is a surprisingly high number of outcome domains, as it is often reported that qualitative studies do not add any outcomes to those already in the literature [27].

In line with other Core Outcome Sets for progressive conditions, it was anticipated that the consensus study would be subdivided according to the different stages of disease progression [28]. However, our findings indicate that outcomes of physical activity overlap greatly across settings and stages of dementia. The initial protocol [28] was therefore changed to a single consensus survey. The potential for qualitative findings to inform the structure and design of a Core Outcome
Set had not been previously identified [5], and it should be taken into account by future Core Outcome Set developers.

\section{Contributions to knowledge about relevant effects of physical activity}

The new outcomes "carer developing friends and getting support"; "meeting individual needs of patient and family"; "becoming interested and gaining interest from others"; "reframing and revisiting the person with dementia" (Table $2 \mathrm{a}$ ) indicate the important role that physical activity has in supporting people living with dementia and their carers in both adapting to the diagnosis and as dementia progresses. The use of physical activity to maintain the identity as that of "someone active" despite the diagnosis is explained in this study, supporting findings from previous qualitative work [14]. However, the use of activity to embrace new roles (as shown, by the new outcome domains "reframing the person with dementia" and "carer making friends and getting support") is a new perspective, indicating that physical activity can be used as a tool, not only to maintain, but also to adapt a sense of self-identity, as dementia progresses. The concept of exercise identity was shown to be key in a recent model of exercise participation for people with chronic conditions, highlighting how patients choose to exercise according to their age and gender identity, social and cultural norms [29]. Physical activity can therefore be used by people living with dementia, as in other chronic conditions, to continuously (re)frame their identity, while living with a progressive condition.

The remaining new outcomes generated by this study reflect potential physical needs of people, either at later stages of dementia, or of those with multiple comorbidities: "improving posture", "preventing incontinence", "managing lower limb oedema" and "managing pressure ulcers". The fact that these are new outcomes, demonstrates the lack of research into physical activity for people with severe dementia [3] and provides new insights into the potential that physical activity may have across stages of disease and for addressing the multi morbidity that often accompanies the progression of dementia [30].

The present study highlights how physical activity interventions can support families living with dementia from early diagnosis and throughout their dementia journeys; a key message in dementia care guidelines and policies [31].

\section{Strengths and limitations}

In-depth interviews were a challenging method for patients at later stages of dementia or those with limited verbal communication, leading to a sample with more carers than people living with dementia, and a relatively small sample of people living with dementia. This is a potential limitation because this Core Outcome Set aims to be applicable to physical activity interventions including people with dementia in all stages of the condition, and with no restrictions in terms 
of communication abilities. Including a higher proportion of carers was a successful strategy to gather the views of those closest to people living with late stage dementia. The present study also informs the next stage of the development of this Core Outcome Set (a consensus study), where a larger sample of people living with dementia will be recruited.

The identification of outcomes from the interviews was conducted by one researcher only. To minimise this potential limitation, the analysis benefited from patient and public involvement through regular reflections with a former carer of someone living with dementia as the data analysis progressed; the final analysis findings were also 'member checked' by four participants [25]. The process of merging the list of outcomes from this qualitative study with the outcomes in the literature was conducted independently by two researchers, increasing the rigor of this stage of data analysis.

\section{Conclusion}

This qualitative study makes an important contribution to Core Outcome Set methodology. By adding 10 outcome domains to the list previously generated from published literature it has demonstrated the important role qualitative methods can play in ensuring outcomes meaningful to patients, carers and professionals are not missed. This study also highlights the value of physical activity across the stages of dementia progression. Whilst confirming findings from previous studies that physical activity can contribute to "Being well and staying well" and "Delivering good quality care" it has also identified an important new finding that physical activity is important in the process of adapting to the diagnosis through "Maintaining identity", "Having a role towards and with others" and "Being connected to the present".

\section{Key messages}

- Qualitative methods ensure relevant outcomes are not missed in Core Outcome Sets.

- Physical activity can enable a constant adaptation of self-identity to patients and carers as the dementia progresses and may bring positive outcomes to those living with severe dementia and/or comorbidities.

- Physical activity for people living with dementia is linked to good quality care, overall wellness, living in the present and being connected with others.

\section{Acknowledgments}

The authors thank Mary Ramsay for her invaluable input and expertise as the main member of "patient and public involvement" for this study, and for her guidance throughout the development of the Core Outcome Set.

Funding: This work was supported by the University of Southampton and Solent NHS Trust, through Clinical Doctoral Research Fellowship to the first author; and Programa Operacional de Competitividade e Internacionalização - POCI, through Fundo Europeu de Desenvolvimento Regional - FEDER (POCI-01-0145-FEDER-007628) and Fundação para a Ciência e Tecnologia under the project UID/BIM/04501/2013 and UID/BIM/04501/2019 to the second author; the remaining authors' time and contributions to this publication were supported by their affiliations only.

Conflicts of interest: None declared.

Registration and ethical approval: This study is part of the development of a Core Outcome Set, registered with the Core Outcome Measures in Effectiveness Trials initiative ${ }^{1}$. Ethical approval was obtained from the ethics committee at the Faculty Health Sciences, University of Southampton (ethics number: 19524). All participants provided informed consent prior to taking part in this study.

\section{Appendix A. Supplementary data}

Supplementary material related to this article can be found, in the online version, at doi:https://doi. org/10.1016/j.physio.2019.05.003.

\section{References}

[1] World Health Organization, Available from: Dementia, a public health priority; 2015 http://www.who.int/ mental_health/neurology/dementia/en/..

[2] Alzheimer's Society, Available from: Outcomes of the James Lind Alliance Dementia priority setting partnership; $2013 \mathrm{https}: / / \mathrm{www}$. alzheimers.org.uk/downloads/download/1427/outcomes_from_the_ james_lind_alliance_priority_setting_partnership:

[3] Gonçalves AC, Cruz J, Marques A, Demain S, Samuel D. Evaluating physical activity in dementia: a systematic review of outcomes to inform the development of a core outcome set. Age Ageing 2018;47(1):34-41.

[4] Williamson PR, Altman DG, Bagley H, Barnes KL, Blazeby JM, Brookes ST, et al. The COMET handbook: version 1.0. Trials; 2017, 18(S3).

[5] Keeley T, Williamson P, Callery P, Jones LL, Mathers J, Jones J, et al. The use of qualitative methods to inform Delphi surveys in core outcome set development. Trials 2016;17(1):230.

[6] Khoo YJ, van Schaik P, McKenna J. The Happy Antics programme: holistic exercise for people with dementia. J Bodyw Mov Ther 2014;18(4):553-8.

[7] Malthouse R, Fox F. Exploring experiences of physical activity among people with Alzheimer's disease and their spouse carers: a qualitative study. Physiotherapy 2014;100(2):169-75.

[8] Suttanon P, Hill KD, Said CM, Byrne KN, Dodd KJ. Factors influencing commencement and adherence to a home-based balance exercise program for reducing risk of falls: perceptions of people with Alzheimer's disease and their caregivers. Int Psychogeriatr IPA 2012;24(7):1172-82.

1 (ACG). 
[9] Yu F, Swartwood RM. Feasibility and perception of the impact from aerobic exercise in older adults with Alzheimer's disease. Am J Alzheimer's Dis Other Dementias 2012;27(6):397-405.

[10] McCaffrey R, Park J, Newman D, Hagen D. The Effect of chair Yoga in older Adults with moderate and severe Alzheimer's disease. Res gerontol Nur 2014;7(4):171-7.

[11] Guzman-Garcia A, Mukaetova-Ladinska E, James I. Introducing a Latin ballroom dance class to people with dementia living in care homes, benefits and concerns: a pilot study. Dementia (London) 2013;12(5):523-35.

[12] Harmer BJ, Orrell M. What is meaningful activity for people with dementia living in care homes? A comparison of the views of older people with dementia, staff and family carers. Aging Mental Health 2008;12(5):548-58.

[13] Soderhamn U, Aasgaard L, Landmark B. Attending an activity center: positive experiences of a group of home-dwelling persons with earlystage dementia. Clin Interv Aging 2014;9:1923-31.

[14] Cedervall Y, Torres S, Aberg AC. Maintaining well-being and selfhood through physical activity: experiences of people with mild Alzheimer's disease. Aging Mental Health 2015;19(8):679-88.

[15] National Institute for Health and Care Excellence. Dementia: supporting people with dementia and their carers in health and social care. NICE guideline. Dementia 2006;(CG42):1-54.

[16] Tong A, Sainsbury P, Craig J. Consolidated criteria for reporting qualitative research (COREQ): a 32-item checklist for interviews and focus groups. Int J Qual Health Care 2007;19(6):349-57.

[17] Palinkas LA, Horwitz SM, Green CA, Wisdom JP, Duan N, Hoagwood K. Purposeful sampling for qualitative data collection and analysis in mixed method implementation research. Adm Policy Mental Health 2013;1(1):1-12.

[18] Folstein MF, Folstein SE, McHugh PR. "Mini-mental state" — a practical method for grading the cognitive state of patients for the clinician. J Psychiatr Rese 1975;12(3):189-98.

[19] Washburn RA, Smith KW, Jette AM, Janney CA. The Physical Activity Scale For The Elderly (PASE): Developemtn And Evaluation. J Clin Epidemiology 1993;46(2):153-62.
[20] Government DoCaL. The English Index of Multiple Deprivation (IMD) 2015 - Guidance. Department of Communities and Local Government; 2015.

[21] Guest G. How many interviews are enough? An experiment with data saturation and variability. Field Methods 2006;18(1):59-82.

[22] Quinn C. Conducting interviews with people with dementia and their caregivers. SAGE Research Methods Cases; 2017.

[23] Dobson C. In: Mental Capacity Act Working Party, editor. Conducting research with people not having the capacity to consent to their participation: a practical guide for researchers. 1st ed. BPS, The British Psychological Society; 2008. p. 1-68.

[24] Braun V, Clarke V. Successful qualitative research — a practical guide for beginners. London: Sage; 2013.

[25] Birt L, Scott S, Cavers D, Campbell C, Walter F. Member checking: a tool to enhance trustworthiness or merely a nod to validation? Qual Health Res 2016;26(13):1802-11.

[26] Beuscher L, Grando VT. Challenges in conducting qualitative research with individuals with dementia. Res Gerontol Nurs 2009;2(1):6-11.

[27] Harman NL, Bruce IA, Kirkham JJ, Tierney S, Callery P, O’Brien K, et al. The importance of integration of stakeholder views in core outcome set development: otitis media with effusion in children with cleft palate. PLoS One 2015;10(6):e0129514.

[28] Gonçalves AC, Marques A, Demain S, Samuel D. Development of a core outcome set to evaluate physical activity interventions for people living with dementia: study protocol. Int $\mathrm{J}$ Ther Rehabil 2018;25(7):346-52.

[29] Pentecost C, Taket A. Understanding exercise uptake and adherence for people with chronic conditions: a new model demonstrating the importance of exercise identity, benefits of attending and support. Health Educ Res 2011;26(5):908-22.

[30] All-Party Parliamentary Group on Dementia. Dementia rarely travels alone: Living with dementia and other conditions. 1st ed. Alzheimer's Society; 2016. p. 1-16.

[31] Department of Health. In: Health Do, editor. Prime Minister's challenge on dementia 2020. 2015.

\section{Available online at www.sciencedirect.com}

\section{ScienceDirect}

